\title{
Evaluation of neutrophyl/lymphocyte ratio, platelet/ lymphocyte ratio and mean platelet volume according to the disease activity index in patients of ankylosing spondylitis
}

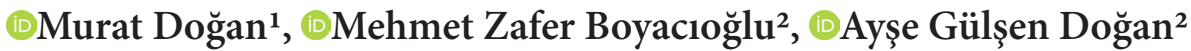 \\ ${ }^{1}$ Hitit University Erol Olçok Training and Research Hospital, Department Of Internal Medicine, Çorum, Turkey \\ ${ }^{2}$ Hitit University Erol Olçok Training and Research Hospital, Department of Physical Medicine and Rehabilitation, Çorum, Turkey
}

Cite this article as: Doğan M, Boyacıŏlu MZ, Doğan AG. Evaluation of neutrophyl/lymphocyte ratio, platelet/lymphocyte ratio and mean platelet volume according to the disease activity index in patients of ankylosing spondylitis. J Health Sci Med 2022; 5(1): $247-251$.

\begin{abstract}
Objective: To determine the relationship between neutrophil/lymphocyte ratio (NLR), platelet/ lymphocyte ratio (PLR) and mean platelet volume (MPV) with acute phase reactants in patients with ankylosing spondylitis (AS) and to show the usability of these parameters in the activation periods and follow-up of the disease.

Material and Method: The demographic data (age, gender) and Bath Ankylosing Spondylitis Disease Activity Index (BASDAI) score of 70 patients who had been followed regularly for at least 1 year and whose diagnosis of AS was definite were recorded. The control group consists of 70 people who do not have any disease. Among the laboratory parameters, neutrophil, platelet, lymphocyte count, C-reactive protein(CRP), erythrocyte sedimentation rate(ESR), NLR, PLR and MPV values were retrospectively checked and recorded.

Results: In our study, a statistically significant difference was found between the AS patients and the control group in MPV, NLR and PLR values. In addition, these values were found to be statistically significantly different between the groups with low disease activity and high disease activity in the AS patient group. There was a weak negative correlation between MPV value and BASDAI, ESR and CRP values. There was no statistically significant correlation between NLR value and ESR and CRP. There was no correlation between PLR value and ESR and CRP.

Conclusion: As a result of our study, NLR, PLR and MPV values are seen as simple, easy and inexpensive markers that can be used to determine disease activity in AS patients.
\end{abstract}

Keywords: Ankylosing spondylitis, NLR, PLR

\section{INTRODUCTION}

Ankylosing spondylitis (AS) is the most common subtype of the Spondyloarthritis (SpA) group that causes inflammatory back pain. It is a common inflammatory disease that causes structural and functional disability (1). AS is an autoimmune disease which is manifested by a variety of genetic and environmental factors influence (2). Axial skeleton and especially sacroiliac joint involvement is prominent in AS (3). The most important complaint is inflammatory back pain. Enthesal and peripheral joint involvement is usually present. The most common extraarticular involvement is uveitis (4).

There is no specific laboratory finding to diagnose patients with AS. Acute phase reactants such as erythrocyte sedimentation rate (ESR) and C-reactive protein (CRP) may be normal in patients with AS, but are frequently used in the diagnosis and treatment of the disease. Rheumatoid factor (RF) and antinuclear antibodies (ANA) are negative (5). Imaging methods are important in the diagnosis and classification of AS (6).

Because AS progresses with periods of exacerbation and remission, some scales are used in disease activation and evaluation of response to treatment.; It evaluates diseasespecific symptoms such as fatigue, spinal and peripheral joint pain, swelling, and morning stiffness.

It is evaluated on scores ranging from $0-10$. An increase in the score indicates an increase in disease activity. It is a reliable and change-sensitive scale developed to evaluate disease activity and progression (7). 
Recently, it has been found that neutrophil, lymphocyte and platelet values, which are a part of the immune system and obtained from the routine complete blood count in the follow-up of rheumatological diseases, are associated with autoimmune diseases, malignancies, inflammatory diseases and chronic diseases. In addition, it has been shown that neutrophil/lymphocyte ratio (NLR) and platelet/lymphocyte ratio (PLR) are associated with ESR, CRP, interleukin-6 (IL-6) and tumor necrosis factoralpha (TNF-alpha) values (8).

Mean platelet volume (MPV) is obtained directly from the hemogram parameter. It decreases in the activation of rheumatological diseases and shows a negative correlation with ESR, CRP. This may indicate that MPV can be used as a negative acute phase reactant. There are differences in studies on NLR and PLR in rheumatological patients.

The aim of our study is to determine the relationship between NLR, PLR, MPV values of our AS patients who are followed up in our outpatient clinic with acute phase reactants according to the disease activation level and to show the usability of these parameters during the activation periods and follow-up of the disease.

\section{MATERIAL AND METHOD}

This study was approved by the university/local human research ethics committee, and all procedures performed in studies involving human participants were conducted in accordance with the ethical standards of the institutional and/or national research committee, the 1964 Declaration of Helsinki and subsequent amendments or comparable ethical standards. Ethics committee approval was obtained from Hitit University Clinical Researchs Ethics Committee for the study (Date: 05.02.2020, Decision No: 169). In our study, the files of AS patients registered in Hitit University Erol Olçok Training and Research Hospital Physical Therapy and Rehabilitation Department between 20182019 were retrospectively scanned. Demographic data (age, gender) and BASDAI score of 70 patients who had been followed up regularly for at least 1 year and whose diagnosis of AS was definite were recorded. The control group consists of 70 people who do not have any disease. The exclusion criteria of the patient group were acute infection, diabetes, cancer or chronic diseases. Laboratory results of the patient and control groups were examined. CRP $(\mathrm{mg} / \mathrm{L})$, ESR $(\mathrm{mm} / \mathrm{h})$ values were obtained from biochemical analysis. Neutrophil (109/L), lymphocyte $\left(10^{9} / \mathrm{L}\right)$, platelet $\left(10^{9} / \mathrm{L}\right)$ counts and MPV $(\mathrm{fL})$ values were obtained from the hemogram analysis. The NLR value was determined by dividing the neutrophil count by the lymphocyte count and the PLR value by dividing the platelet count by the lymphocyte count. Clinical evaluation and laboratory data of only one examination data of a patient were included in the study. The patient group was divided into two groups with BASDAI score below 4 as low activity and 4 and above high activity. CRP, ESR, platelet, MPV, NLR and PLR values obtained from routine hemogram analysis were compared with the disease and control groups. In addition, these values were compared in the patient group according to the BASDAI score.

\section{Statistical Analysis}

Statistical analyzes were performed using a package program called SPSS (IBM SPSS Statistics 24). Frequency tables and descriptive statistics were used in the interpretation of the findings. Parametric methods were used for measurement values suitable for normal distribution. In accordance with parametric methods, "IndependentSample-t" test (t-table value) method was used to compare the measurement values of two independent groups. Nonparametric methods were used for measurement values that are not suitable for normal distribution. In accordance with non-parametric methods, "Mann-Whitney U" test (Z-table value) method was used to compare the measurement values of two independent groups. The expected Pearson- $\chi 2$ and continuity correction cross tables were used to examine the relationships between two qualitative variables. "Pearson" correlation coefficient in examining the relationship of two quantitative data with normal distribution; "Spearman" correlation coefficient was used to examine the relationship of two quantitative data that do not have normal distribution. Binary Logistic Regression: Backward LR model was used to determine the factors affecting high disease activity.

\section{RESULTS}

There is no statistically significant relationship between the groups and gender $(p>0.05)$. Groups are genderneutral and homogeneous. A statistically significant relationship was found between the BASDAI classes of the patients and their gender $(\chi 2=6.121 ; \mathrm{p}=0.013)$. It was found that $23(82.1 \%)$ of the women were in the low disease activity class and $21(50.0 \%)$ of the men were in the high disease activity class. It was determined that those with low disease activity level were predominantly female, and those with high disease activity level were predominantly male (Table $\mathbf{1}$ ).

\begin{tabular}{|c|c|c|c|c|c|}
\hline \multirow[b]{2}{*}{ Variable } & \multicolumn{2}{|c|}{ Female } & \multicolumn{2}{|c|}{ Male } & \multirow{2}{*}{$\begin{array}{l}\text { Statistical } \\
\text { analysis* } \\
\text { Possibility }\end{array}$} \\
\hline & $\mathbf{n}$ & $\%$ & $\mathbf{n}$ & $\%$ & \\
\hline \multicolumn{6}{|l|}{ Group } \\
\hline Ankylosing spondylitis & 28 & 50.0 & 42 & 50.0 & $\chi^{2}=0.000$ \\
\hline Control & 28 & 50.0 & 42 & 50.0 & $\mathrm{p}=1.000$ \\
\hline \multicolumn{6}{|l|}{ Patient BASDAI class } \\
\hline Low activity $(<4)$ & 23 & 82.1 & 21 & 50.0 & $\chi^{2}=6.121$ \\
\hline High activity $(\geq 4)$ & 5 & 17.9 & 21 & 50.0 & $\mathrm{p}=0.013$ \\
\hline
\end{tabular}


A statistically significant difference was found between the groups in terms of CRP, MPV, NLR, Platelet and PLR values $(\mathrm{p}<0.05)$. The CRP, NLR, Platelet and PLR values of those in the ankylosing spondylitis group were found to be statistically significantly higher than those in the control group, and the MPV value was significantly lower (Table 2).

\begin{tabular}{|c|c|c|c|}
\hline \multirow{2}{*}{ Variable } & $\begin{array}{l}\text { Ankylosing } \\
\text { spondylitis } \\
(\mathbf{n}=70)\end{array}$ & $\begin{array}{c}\text { Control } \\
(n=70)\end{array}$ & \multirow[t]{2}{*}{$p$ value } \\
\hline & $\mathrm{X}^{-} \pm \mathrm{SS}$ & $\mathrm{X}^{-} \pm \mathrm{SS}$ & \\
\hline Age (years) & $41.08 \pm 10.25$ & $42.54 \pm 10.45$ & 0.052 \\
\hline Disease Duration (years) & $6.25 \pm 2.4$ & - & \\
\hline $\mathrm{CRP}(\mathrm{mg} / \mathrm{L})$ & $10.74 \pm 14.22$ & $4.60 \pm 3.37$ & 0.020 \\
\hline $\operatorname{ESR}(\mathrm{mm} / \mathrm{h})$ & $14.95 \pm 13.87$ & $12.70 \pm 10.14$ & 0.622 \\
\hline Neutrophil $\left(10^{9} / \mathrm{L}\right)$ & $4.33 \pm 1.35$ & $4.07 \pm 1.30$ & 0.245 \\
\hline Lymphocyte (109/L) & $2.29 \pm 0.79$ & $2.46 \pm 0.64$ & 0.055 \\
\hline NLR & $2.06 \pm 0.89$ & $1.75 \pm 0.71$ & 0.010 \\
\hline Platelet $\left(10^{9} / \mathrm{L}\right)$ & $272.07 \pm 64.60$ & $250.71 \pm 60.92$ & 0.022 \\
\hline $\mathrm{MPV}(\mathrm{fL})$ & $9.75 \pm 1.35$ & $10.47 \pm 0.93$ & 0.004 \\
\hline PLR & $132.40 \pm 55.05$ & $110.21 \pm 51.27$ & 0.010 \\
\hline \multicolumn{4}{|c|}{$\begin{array}{l}\text { * IndependentSample-t test was used for comparing the measurement values of two } \\
\text { independent groups in the data with normal distribution, and the "Mann-Whitney } \\
\text { U" test statistics were used to compare the measurement values of two independent } \\
\text { groups in the data without normal distribution. }\end{array}$} \\
\hline
\end{tabular}

While there was no statistically significant difference in age according to the BASDAI classes of the patients ( $p>0.05)$, a statistically significant difference was found in terms of CRP, ESR, platelet, NLR, MPV, PLR values $(p<0.05)$. CRP, ESR, platelet, NLR, and PLR values of those in the high disease activity group were significantly higher, while MPV was significantly higher in the low disease activity group (Table 3 ).

There was a positive correlation between BASDAI score and CRP, ESR and a weak negative correlation with MPV. There was a weak correlation between CRP values and ESR in the positive direction and a negative correlation with MPV. In the correlation analysis of ESR values, negative weak correlation with MPV was obtained.

Table 3. Comparison of parameters in the patient group according to BASDAI classes.

\begin{tabular}{|lccc}
\multirow{2}{*}{$\begin{array}{r}\text { BaSDAI } \\
\text { Variable }\end{array}$} & $\begin{array}{c}\text { Low disease } \\
{[<\mathbf{4}](\mathbf{n}=\mathbf{4 4})}\end{array}$ & $\begin{array}{c}\text { High disease } \\
{[\geq \mathbf{4}](\mathbf{n}=\mathbf{2 6})}\end{array}$ & $\begin{array}{c}\text { Statistical } \\
\text { analysis }\end{array}$ \\
\cline { 2 - 3 } Age(years) & $40.80 \pm 10.55$ & $41.58 \pm 9.90$ & $\begin{array}{c}\mathrm{t}=-0.306 \\
\mathrm{X}=0.760\end{array}$ \\
CRP & $4.42 \pm 2.90$ & $21.43 \pm 18.82$ & $\mathrm{p}=0.000$ \\
ESR & $11.41 \pm 9.59$ & $20.92 \pm 17.72$ & $\mathrm{p}=0.018$ \\
NLR & $1.95 \pm 0.84$ & $2.26 \pm 0.94$ & $\mathrm{p}=0.047$ \\
Platelet & $276.05 \pm 55.40$ & $365.35 \pm 78.52$ & $\mathrm{P}<0.001$ \\
MPV & $10.24 \pm 0.88$ & $9.90 \pm 1.92$ & $\mathrm{p}=0.003$ \\
PLR & $131.76 \pm 53.69$ & $133.46 \pm 58.35$ & $\mathrm{p}=0.008$
\end{tabular}

"Independent Sample-t" test (t-table value) for comparing the measurement values of two independent groups in the data with normal distribution; "Mann-Whitney U" test statistics were used to compare the measurement values of two independent groups in the data that did not have a normal distribution.
There was a weak positive correlation between NLR and PLR value, and a weak negative correlation between MPV and its value (Table 4).

\begin{tabular}{|c|c|c|c|c|c|c|c|}
\hline \multicolumn{2}{|c|}{$\begin{array}{l}\text { Correlation } \\
(n=70) \text { Variable }\end{array}$} & \multirow{2}{*}{$\begin{array}{c}\text { BASDAI } \\
\text { score } \\
1.000\end{array}$} & \multirow{2}{*}{$\begin{array}{l}\text { CRP } \\
0.705 \\
0.000\end{array}$} & \multirow{2}{*}{$\begin{array}{l}\text { ESR } \\
0.298 \\
0.012\end{array}$} & \multirow{2}{*}{$\begin{array}{l}\text { NLR } \\
0.195 \\
0.006\end{array}$} & \multirow{2}{*}{$\begin{array}{c}\text { PLR } \\
0.238 \\
0.034\end{array}$} & \multirow{2}{*}{$\begin{array}{c}\text { MPV } \\
-0.305 \\
0.020\end{array}$} \\
\hline $\begin{array}{l}\text { BASDAI } \\
\text { score }\end{array}$ & $\begin{array}{l}\mathrm{r} \\
\mathrm{p}\end{array}$ & & & & & & \\
\hline CRP & $\begin{array}{l}\mathrm{r} \\
\mathrm{p}\end{array}$ & & $\begin{array}{c}1.000 \\
-\end{array}$ & $\begin{array}{l}0.467 \\
0.000\end{array}$ & $\begin{array}{l}0.225 \\
0.061\end{array}$ & $\begin{array}{l}0.068 \\
0.577\end{array}$ & $\begin{array}{c}-0.285 \\
0.033\end{array}$ \\
\hline ESR & $\begin{array}{l}\mathrm{r} \\
\mathrm{p}\end{array}$ & & & $\begin{array}{c}1.000 \\
-\end{array}$ & $\begin{array}{l}0.160 \\
0.184\end{array}$ & $\begin{array}{l}0.226 \\
0.060\end{array}$ & $\begin{array}{c}-0.301 \\
0.023\end{array}$ \\
\hline NLR & $\begin{array}{l}\mathrm{r} \\
\mathrm{p}\end{array}$ & & & & $\begin{array}{c}1.000 \\
-\end{array}$ & $\begin{array}{l}0.421 \\
0.000\end{array}$ & $\begin{array}{c}-0.299 \\
0.049\end{array}$ \\
\hline PLR & $\begin{array}{l}\mathrm{r} \\
\mathrm{p}\end{array}$ & & & & & $\begin{array}{c}1.000 \\
-\end{array}$ & $\begin{array}{c}-0.044 \\
0.113\end{array}$ \\
\hline
\end{tabular}

\section{DISCUSSION}

Ankylosing spondylitis (AS) is a common rheumatic disease that predominantly affects the axial skeleton, with structural and functional disability causing inflammatory low back pain. More than $80 \%$ of patients usually start to show their first symptoms before the age of 30 . Men are significantly more affected by the disease than women. In our study, a statistically significant relationship was found between BASDAI classes and gender. It was determined that those with low disease activity level were predominantly female, and those with high disease activity level were predominantly male.

MPV shows the average circulating platelet size obtained from a complete blood count. Its normal value is 7.5$11.5 \mathrm{fl}$. It is a parameter indicative of platelet function and activity, and it decreases with the pressure of proinflammatory cytokines and acute phase markers on the bone marrow in inflammation and shows a negative correlation in the inflammatory process $(9,10)$. In studies conducted with RA patients, MPV levels were found to be lower in the patient group compared to the control group, and an inverse correlation was found with disease activity scores (11).

Negative correlations were found with BASDAI in AS patients, with CRP in psoriatic arthritis patients, and with ESR in SLE patients $(12,13)$. Although many studies have suggested that MPV decreases in inflammatory diseases and it can be studied as a negative marker, some studies have found that MPV value is similar between AS patients and the control group and does not correlate with CRP (14). In our study, a statistically significant difference was found in MPV value between AS patients and the control group. MPV level was found to be significantly lower in AS patients. In addition, MPV value was found 
to be statistically significantly higher in AS patients, in the group with low disease activity. There was a weak negative correlation between MPV value and BASDAI, ESR and CRP values.

It suggested that the increase in the number of neutrophils and platelets in the systemic circulation in the presence of inflammation, and the decrease in the number of lymphocytes, NLR and PLR parameters can be used as a marker in rheumatic diseases and in the activation periods of these diseases. The NLR value is an easy, cheap and simple parameter obtained by dividing the number of neutrophils obtained from the complete blood count by the number of lymphocytes and the PLR value by the number of lymphocytes (15). In recent studies, there are many studies showing the usability of NLR and PLR as inflammatory and activity markers in inflammatory rheumatic diseases. In some studies, it was reported that the NLR value was higher in the active disease group than in the inactive disease group according to the BASDAI score and there was a positive correlation between the BASDAI score and the NLR value. Contrary to these studies, there are also studies that could not find a correlation between BASDAI and NLR $(10,16,17)$. It is included in studies in which a significant positive correlation was found between NLR values and ESR and CRP levels (17). In our study, the NLR values were found to be statistically significantly different between the AS patients and the control group, and the AS group with high disease index and the AS group with low disease index. In our study, no statistically significant correlation was observed between NLR value and ESR and CRP.

PLR has been found as an inflammatory marker and a valuable prognostic factor in some malignancies and patients diagnosed with heart failure $(17,18)$. In a study conducted with AS patients, a significant statistical difference was found between the patient group and the control group in PLR value (17). In a meta-analysis study, PLR values did not differ significantly between the patient and control groups (14). In some correlation studies, a positive correlation was found between PLR and ESR and CRP $(16,19)$. In our study, the PLR value was found to be statistically significantly different in both the patient group and patients with AS with high activity index. There was no correlation between PLR value and ESR and CRP.

\section{CONCLUSION}

As a result of our study, NLR, PLR and MPV values are seen as simple, easy and inexpensive markers that can be used to determine disease activity in AS patients. The limitation of our study is that it is retrospective. These parameters may also guide new indices to be investigated in future studies for AS diseases, and we believe that they will contribute to the literature.

\section{ETHICAL DECLARATIONS}

Ethics Committee Approval: Ethics committee approval was obtained from Hitit University Clinical Researchs Ethics Committee (Date: 05.02.2020, Decision No: 169).

Informed Consent: Because the study was designed retrospectively, no written informed consent form was obtained from patients.

Referee Evaluation Process: Externally peer-reviewed.

Conflict of Interest Statement: The authors have no conflicts of interest to declare.

Financial Disclosure: The authors declared that this study has received no financial support.

Author Contributions: The authors declare that they have all participated in the design, execution, and analysis of the paper, and that they have approved the final version.

\section{REFERENCES}

1. Braun J, Sieper J. Ankylosing spondylitis. The Lancet 2007; 369: 1379-90.

2. Zhu W, He X, Cheng K, et al. Ankylosing spondylitis: etiology, pathogenesis, and treatments. Bone Res 2019; 7: 1-16.

3. Dougados M, Baeten D. Spondyloarthritis. Lancet 2011; 377: 2127-37.

4. Reveille J. Clinical Features of Ankylosing Spondylitis. In: Hochberg MC, Silman AJ, Smolen JS, Weinblatt ME, Weisman MH. Rheumatology (4th ed) Elsevier Publishers; 2008: 1109-14.

5. Raychaudhuri SP, Deodhar A. The classification and diagnostic criteria of ankylosing spondylitis. J Autoimmun 2014; 48: 128-33.

6. Elyan M, Khan MA. Diagnosing ankylosing spondylitis. J Rheumatol Supp 2006; 78: 12-23.

7. Spoorenberg A, van der Heijde D, de Klerk E, et al. Relative value of erythrocyte sedimentation rate and $\mathrm{C}$-reactive protein in assessment of disease activity in ankylosing spondylitis. J Rheumatol 1999; 26: 980-4.

8. Zochling J. Measures of symptoms and disease status in ankylosing spondylitis: Ankylosing Spondylitis Disease Activity Score (ASDAS), Ankylosing Spondylitis Quality of Life Scale (ASQoL), Bath Ankylosing Spondylitis Disease Activity Index (BASDAI), Bath Ankylosing Spondylitis Functional Index (BASFI), Bath Ankylosing Spondylitis Global Score (BAS-G), Bath Ankylosing Spondylitis Metrology Index (BASMI), Dougados Functional Index (DFI), and Health Assessment Questionnaire for the Spondylarthropathies (HAQ-S). Arthritis Care Res (Hoboken). 2011; 63: S47-S58.

9. Abd-Elazeem MI, Mohamed RA. Neutrophil-lymphocyte and platelet-lymphocyte ratios in rheumatoid arthritis patients: Relation to disease activity. Egypt Rheumatol 2018; 40(4): 227 31

10.Schmoeller D, Picarelli MM, Paz Munhoz T, Poli de Figueiredo CE, Staub HL. Mean platelet volume and immature platelet fraction in autoimmune disorders. Front Med 2017; 4: 146.

11. Mercan R, Bitik B, Tufan A, et al. The association between neutrophil/lymphocyte ratio and disease activity in rheumatoid arthritis and ankylosing spondylitis. J Clin Lab Anal 2016; 30: 597-601.

12.Şahin A, Yetişgin A, Şahin M, Durmaz Y, Cengiz AK. Can mean platelet volume be a surrogate marker of inflammation in rheumatic diseases? West Indian Med J 2016; 65: 165-9. 
13. Sen BB, Rifaioglu EN, Ekiz O, Inan MU, Sen T, Sen N. Neutrophil to lymphocyte ratio as a measure of systemic inflammation in psoriasis. Cutan Ocul Toxicol 2014; 33: 223-7.

14. Seng JJB, Kwan YH, Low LL, Thumboo J, Fong WSW. Role of neutrophil to lymphocyte ratio (NLR), platelet to lymphocyte ratio (PLR) and mean platelet volume (MPV) in assessing disease control in Asian patients with axial spondyloarthritis. Biomarkers 2018; 23: 335-8

15.Song GG, Lee YH. Red cell distribution width, platelet-tolymphocyte ratio, and mean platelet volume in ankylosing spondylitis and their correlations with inflammation: A metaanalysis. Modern Rheumatol 2019: 1-6

16. Gökmen F, Akbal A, Reşorlu H, et al. Neutrophil-lymphocyte ratio connected to treatment options and inflammation markers of ankylosing spondylitis. J Clin Lab Anal 2015; 29: 294-8.

17. Aşkın A. Ankilozan spondilit hastalarında nötrofil/lenfosit oran1, trombosit/lenfosit oran1 ve ortalama trombosit hacminin değerlendirilmesi. Cukurova Med J 2016; 41: 479-84.

18. Boyraz İ, Koç B, Boyacı A, Tutoğlu A, Sarman H, Özkan H. Ratio of neutrophil/lymphocyte and platelet/lymphocyte in patient with ankylosing spondylitis that are treating with anti-TNF. International journal of clinical and experimental medicine 2014 7: 2912

19. Templeton AJ, Ace O, McNamara MG, et al. Prognostic role of platelet to lymphocyte ratio in solid tumors: a systematic review and meta-analysis. Cancer Epidemiol Biomarkers Prev 2014; 23 1204-12.

20. Bozan N, Alpaycı M, Aslan M, et al. Mean platelet volume, red cell distribution width, platelet-to-lymphocyte and neutrophilto- lymphocyte ratios in patients with ankylosing spondylitis and their relationships with high-frequency hearing thresholds. Eur Arch Oto-Rhino-Laryngol 2016; 273: 3663-72. 